\title{
$A B C$ messages for HIV prevention in Kenya: Clarity and confusion, barriers and facilitators
}

Julie Pulerwitz

Tiffany Lillie

Louis Apicella

Population Council

Ann P. McCauley

Tobey C. Nelson

See next page for additional authors

Follow this and additional works at: https://knowledgecommons.popcouncil.org/departments_sbsr-hiv

Part of the Demography, Population, and Ecology Commons, Gender and Sexuality Commons, Health Policy Commons, Immune System Diseases Commons, International Public Health Commons, Medicine and Health Commons, Public Health Education and Promotion Commons, Social Policy Commons, and the Virus Diseases Commons How does access to this work benefit you? Let us know!

\section{Recommended Citation}

Pulerwitz, Julie, Tiffany Lillie, Louis Apicella, Ann P. McCauley, Tobey C. Nelson, Simon Ochieng, Peter Mwarogo, Karusa Kiragu, and Edward Kunyanga. 2006. "ABC messages for HIV prevention in Kenya: Clarity and confusion, barriers and facilitators," Horizons Final Report. Washington, DC: Population Council. 


\section{Authors}

Julie Pulerwitz, Tiffany Lillie, Louis Apicella, Ann P. McCauley, Tobey C. Nelson, Simon Ochieng, Peter Mwarogo, Karusa Kiragu, and Edward Kunyanga 


\section{SImpact}

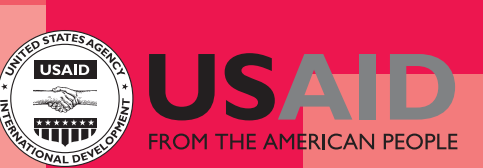

Hgrizons N

\section{ABC Messages for HIV Prevention in Kenya: Clarity and Confusion, Barriers and Facilitators}

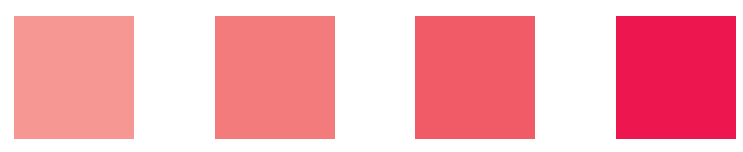

Horizons Program IMPACT 


\title{
ABC Messages for HIV Prevention in Kenya: Clarity and Confusion, Barriers and Facilitators
}

\author{
J ulie Pulerwitz ${ }^{1}$, Tiffany Lillie ${ }^{2}$, Lou Apicella ${ }^{3}$, \\ Ann McCauley ${ }^{4}$, Tobey Nelson ${ }^{4}$, Simon Ochieng ${ }^{2}$, \\ Peter Mwarogo ${ }^{2}$, Karusa Kiragu ${ }^{1}$, and Edward Kunyanga ${ }^{2}$
}

Institutional affiliation at the time of the study:

${ }^{1}$ Horizons/PATH

${ }^{2} \mathrm{FHI} / \mathrm{IMPACT}$

${ }^{3}$ Horizons/Population Council

${ }^{4}$ Horizons/ICRW 


\section{Acknowledgments}

The authors would like to thank Helen Odindo, consultant, for her tremendous assistance with data collection. Also, the authors would like to thank the reviewers of the report, who provided such helpful input, including Michael Cassell, USAID; Naomi Rutenberg, Horizons/Population Council; Colleen Conroy, formerly of PATH; Paul Nary, FHI; and John McWilliams, FHI. A special acknowledgment goes to Carol Larivee, formerly of FHI, who encouraged and supported the study team, and who was a major impetus behind the study.

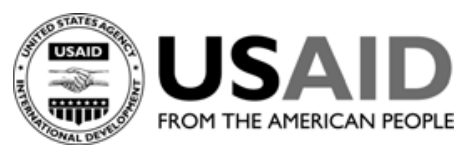

This project was funded by the Horizons Program. Horizons is implemented by the Population Council in collaboration with the International Center for Research on Women, International HIV/AIDS Alliance, PATH, Tulane University, Family Health International, and Johns Hopkins University. Horizons is funded by the President's Emergency Plan for AIDS Relief through the U.S. Agency for International Development, under the terms of HRN-A-000-97-00012-00. The opinions expressed herein are those of the authors and do not necessarily reflect the views of the U.S. Agency for International Development.

Published in June 2006.

\section{(2) Population Council}

The Population Council is an international, non-profit, nongovernmental institution that seeks to improve the well-being and reproductive health of current and future generations around the world and to help achieve a humane, equitable, and sustainable balance between people and resources. The Council conducts biomedical, social science, and public health research and helps build research capacities in developing countries. Established in 1952, the Council is governed by an international board of trustees. Its New York headquarters supports a global network of country offices.

Copyright 2006 The Population Council Inc.

Suggested citation: Pulerwitz, Julie, Tiffany Lillie, Lou Apicella, Ann McCauley, Tobey Nelson, Simon Ochieng, Peter Mwarogo, Karusa Kiragu, and Edward Kunyanga. 2006. "ABC messages for HIV prevention in Kenya: Clarity and confusion, barriers and facilitators,” Horizons Final Report. Washington, DC: Population Council.

This document may be reproduced in whole or in part without permission of the Population Council provided full source citation is given and the reproduction is not for commercial purposes. 


\section{Table of Contents}

$\begin{array}{ll}\text { Executive Summary } & 4\end{array}$

$\begin{array}{ll}\text { Introduction } & 6\end{array}$

$\begin{array}{lr}\text { Methods } & 8\end{array}$

$\begin{array}{ll}\text { Study overview } & 8\end{array}$

Sociodemographic profile $\quad 11$

$\begin{array}{ll}\text { Results } & 14\end{array}$

HIV awareness and knowledge $\quad 14$

$\begin{array}{ll}\text { Sexual behavior } & 15\end{array}$

Awareness of the ABCs for HIV prevention $\quad 17$

$\begin{array}{ll}\text { Overall clarity of the ABCs } & 17\end{array}$

Attitudes toward the ABCs $\quad 19$

Barriers to the successful implementation of the ABCs 21

Facilitators the successful implementation of the ABCs 27

Sources of HIV-related information $\quad 29$

Discussion and Recommendations 33

$\begin{array}{ll}\text { References } & 37\end{array}$ 



\section{Executive Summary}

A great deal of attention has been focused recently on the promotion of the "ABCs" of HIV preventionbeing abstinent and/or delaying sex, remaining faithful to one sexual partner and/or reducing the number of sexual partners, and consistently using condoms during sex. Yet even as programs that focus on the ABCs to prevent sexual HIV transmission are rolled out, questions remain about how well different groups in varied cultural contexts actually understand the terms, as well as how best to address challenges to adopting the $\mathrm{ABC}$ behaviors.

The Horizons Program and FHI/IMPACT developed a collaborative research study in 2004 to explore how adults and youth in Kenya define and perceive the ABC terms and behaviors. Additional objectives of the study were to identify attitudes and norms around the ABC behaviors that influence perceptions of them, and the role of important actors in transmitting messages about them. Findings highlight potential challenges in promoting each of the ABC behaviors, as well as some positive elements that can be built upon when developing programs.

\section{Study Methods}

For findings to be relevant to a wide audience, two groups were selected to represent general youth and adult populations: working adults at flower farms and in-school youth. Surveys were administered to 538 flower farm workers ages 18-49 and 1,365 in-school youth ages 13-19 in two communities in the Nakuru district, Naivasha and Molo. In addition, multiple focus group discussions were held with both groups.

As part of the surveys, respondents were asked whether they had heard of "abstinence," "being faithful," and "condom use" in the context of HIV prevention. Study participants were also asked to write a definition for each term. Responses were coded as correct, partially correct, incorrect, respondent states that he/she does not know, and answer not a definition. The non-definition answers were further examined for themes such as value judgments indicative of attitudes toward the behavior (e.g., condom use is ineffective; abstinence is good because it prevents AIDS).

\section{Key Findings}

\section{Most respondents are familiar with the $\mathrm{ABC}$ terms.}

Both adults and youth had an almost universal awareness of HIV, and the great majority had heard the ABC terms used in the context of HIV prevention. Specifically, 88 percent of adults and 84 percent of youth had heard of "abstinence," 97 percent of adults and 93 percent of youth had heard of "be faithful," and 95 percent of adults and 84 percent of youth had heard of "condom use." 


\section{Hgrizons}

\section{Abstinence is the most clearly understood term.}

When asked to define the ABC behaviors in open-ended survey questions, many respondents did not have a clear understanding of the terms. Both groups understood the term "abstinence” the best, and generally described it as not having sex. Compared to adults, youth were more likely to supply a correct answer (46 vs. 39 percent).

Respondents often misunderstood and confused the term "being faithful" with other concepts and qualities, such as loyalty to a friend, being a trustworthy person, or trusting God. When defined in the context of a sexual relationship, it was commonly confused with trusting your partner, or having faith that your partner was faithful. Youth were more likely to confuse the term, with only 23 percent answering the question correctly compared to 35 percent of adults.

While the concept of condom use appeared to be relatively well understood, only 17 percent of adults and 13 percent of youth supplied a correct definition of "consistent condom use.” Many youth, particularly younger students, responded with an opinion of condom use rather than a definition. Many adults (43 percent) did not answer the question.

Overall, adults tended to define the ABCs more accurately than youth. Men and women, younger (less than 15 years) and older (15 years or over) youth, and sexually experienced and non-experienced youth tended to have similar clarity about the ABCs.

\section{Negative opinions toward condom use are widespread.}

When survey respondents supplied an opinion about the ABCs instead of a definition, they usually cited the advantages and disadvantages of the behaviors. The predominant themes related to condom use, particularly among male and female youth, were that they are ineffective, likely to spread HIV, physically harmful, and immoral. As a group, adults both reported the benefits of preventing HIV and other STIs through condom use and held the view that condoms were ineffective.

Respondents expressed many and varied reasons for their negative views toward condom use as well as numerous barriers to their use. For example, adults and youth reported that individuals, including educators, and the media taught them that condoms were ineffective or regularly burst.

Female flower farm workers sometimes reported experiences of their male partners intentionally damaging condoms during sex so that they could successfully insist upon not using them, and male respondents concurred that this takes place. Both male and female students shared the opinion that since youth their age should not be having sex, condom use was inappropriate or naughty. Male and female adults reported that condoms were unpopular and difficult to implement because they reduced their sexual pleasure, or because raising the issue with their partner implied a "lack of trust." 


\section{Abstinence and being faithful are viewed positively, but numerous barriers exist.}

Respondents perceived abstinence and being faithful very positively and as widely encouraged. During focus group discussions, participants further emphasized positive attitudes toward abstinence and being faithful and offered reasons for them, such as that the behaviors are supported by society or that they are morally acceptable.

Yet the discussions were frequently tempered with statements on the barriers to the behaviors, as respondents offered reasons why they were difficult or impossible to implement in actuality. During focus group discussions, respondents from varied backgrounds - men and women, girls and boys - mentioned the driving need for sex and an inability to control sexuality. In addition, both male and female adults expressed their skepticism toward practicing abstinence and faithfulness to one partner, particularly on the part of men.

Respondents also expressed a sense of fatalism-HIV is so common that there is no way to avoid infection nor any need to engage in risk reduction behaviors such as mutual monogamy. Other respondents believed in potential negative physical repercussions of not having sex, such as body pains and an inability to urinate.

\section{Gender dynamics play a crucial role in the adoption of the $A B C$ behaviors.}

Gender was an important theme that was raised by all groups. For example, a number of factors affecting women and girls were raised as barriers to the ABC behaviors. Female flower farm workers and some female youth highlighted pressure to have sex, often due to economic hardships. Another key factor was gender-based power dynamics inhibiting women's ability to negotiate issues related to sexual behavior. Examples included the decision to have sex or not, gender norms related to men needing to maintain multiple sexual partners, and the successful negotiation of condom use. Concerns about gender-based violence and rape of young girls and women were also commonly cited as insurmountable barriers to the adoption of the ABCs.

Male respondents, including both flower farm workers and in-school youth, often discussed how women prompt and encourage sexual activity through their own behaviors, such as by dressing provocatively.

\section{Respondents hear mixed messages about the ABCs.}

Community-driven messages included both that mutual monogamy was a good idea to prevent HIV, and that something was "wrong” if men did not have multiple sexual partners. Both flower farm workers and in-school youth indicated that different institutions sometimes sent different messages, which they found confusing - such as public health messages promoting one behavior while religious institutions promoted another. Another area of confusion, especially for youth, was how some groups promoted certain behaviors even though many people in the groups did not practice those behaviors themselves. 


\section{Hgrizons}

\section{Respondents prefer interpersonal sources of information.}

The radio was reported as a main source of HIV information for both adults and youth. However, when asked about the best way to transmit key ABC messages, both adults and youth stated a preference for interpersonal and interactive methods, such as workshops. Radio announcements were found to be too general and respondents said they liked the opportunity to discuss issues in detail and to have their questions addressed. Both groups also commonly reported receiving information on the ABCs from friends; however, they were not sure of the reliability of such information.

\section{Conclusions and Recommendations}

HIV prevention programs that incorporate ABC messages—both in Kenya and elsewhere-should consider a number of lessons highlighted in this study. Although most respondents had heard of the ABCs in the context of HIV prevention, much confusion surrounding the actual behaviors existed. This is perhaps due in part to respondents receiving conflicting ABC-related messages from different sources. Programs should clearly define the behaviors with locally appropriate language and coordinate messages so they are consistent, or at least not conflicting. This recommendation is not new but bears repeating, given the study's findings.

The findings also provide a strong rationale for choosing approaches that extend beyond the simple provision of prescriptive ABC messages to more broadly influencing the social norms and policies that serve as barriers to the adoption of safer behaviors. These include addressing perceptions of masculinity and norms of male behavior, targeting the social and structural causes of transactional and crossgenerational sex, and curtailing gender-based violence.

Abstinence and being faithful to one sexual partner were behaviors supported by study respondents, yet numerous barriers to the behaviors were described, especially for women and girls. HIV prevention activities can build upon the existing support for the behaviors. Complementary activities to address the barriers and enable individuals to enact the behaviors, if they choose to do so, would be vital components of effective HIV prevention programs.

Negative beliefs about and discomfort with condoms should be addressed to successfully implement a balanced ABC approach. Debates about the appropriateness and effectiveness of condom use have a longstanding history in the Kenyan context; it is clear that study respondents have received inconsistent and negative messages about condoms, especially in-school youth. Sexually active youth and adults do not have accurate and needed information, and this needs to be addressed.

Preferred sources of HIV information were interactive and interpersonal, so programs should include related activities. Respondents also indicated that they most often spoke to friends about the ABCs, but that friends were not necessarily the most reliable or trusted source of information. Peer education programs to enhance reliability of information from peers, combined with more traditional sources of health information, such as schools and clinics, could be important strategies in Kenya.

An ongoing HIV prevention intervention in Naivasha, being implemented by FHI, builds upon the study findings by bringing together various NGO, civil, and faith-based organizations to coordinate a 
prevention strategy that is balanced and does not include messages that contradict one another. The intervention focuses on interactive and interpersonal activities, such as discussion groups and street theater. In-depth discussions about sensitive social norms, relationship scenarios, and sexual behavior take place during these activities. The intervention also uses other communication channels, such as billboards and IEC materials, to communicate and reinforce ABC messages on a more massive scale. And finally, there are ongoing attempts to integrate complementary interventions, such as gender-based violence reduction programs. 


\section{Hgrizons}

\section{Introduction}

A great deal of attention has been focused recently on the promotion of the "ABCs" for HIV preventionbeing abstinent or delaying sex, remaining faithful to one sexual partner or reducing the number of sexual partners, and consistently using condoms during sex. Yet even as programs that focus on the ABCs to prevent sexual HIV transmission are rolled out, questions remain about how well different groups in varied cultural contexts actually understand the terms, as well as how best to address challenges to adopting the $\mathrm{ABC}$ behaviors.

Supporters of the ABCs have argued that the successful reduction in HIV prevalence in Uganda is due to the promotion and practice of each of the ABC behaviors (Altman 2005; Green 2003; Halperin 2004; Shelton et al. 2004; Stoneburner and Low-Beer 2004). Others have argued that the emphasis on a few behaviors is too simplistic (Barnett and Parkhurst 2005; The Economist 2005; Osborne 2005; Rothenberg, Potterat, and Koplan 2005; Wawer et al. 2005). In particular, many have highlighted that women and girls often do not have the power to negotiate the ABCs and argue that other contextual factors, such as poverty, need to be taken into account (Barnett and Parkhurst 2005; Osborne 2005).

This dialogue highlights potential confusion about whether the ABCs are program strategies per se, or instead, behavioral objectives. If the ABCs are interpreted as strategies, then there is the danger of limiting HIV prevention programs to only disseminating information about the ABC behaviors. If the $\mathrm{ABCs}$ are considered behavioral objectives, there are many possible ways to meet them, and a series of wide-ranging interventions may be employed to enable both women and men to choose from among these behaviors.

Most authors seem to agree that it is important to have a balanced approach in HIV programming that addresses all risk reduction behaviors-including the ABCs—and that messages related to the ABCs need to be appropriately tailored and targeted for different audiences and different cultural contexts. As an April 2004 editorial in the British Medical Journal argued, the most effective HIV prevention strategies are ones that are community-driven and able to meet the unique needs of diverse communities (Wilson 2004). Yet, there have been concerns raised about how people in different settings perceive the abstinence, be faithful, and condom use terms and behaviors. For example, a study in Namibia found that many youth thought that "abstinence" meant "to be absent," and "being faithful" was not understood as being linked to sexual fidelity and was instead associated with religion (PR Newswire 2003).

In 2003, the Horizons Program sponsored a one-day technical meeting to develop and set priorities for an operations research agenda to study effective behavior change strategies for HIV risk reduction, particularly addressing the ABC behaviors (Pulerwitz, van Dam, and Phillips-Hamblett 2003). Representatives from more than 20 organizations, programs, and universities involved in prevention research and programming, including IMPACT, coordinated by Family Health International (FHI), discussed behavioral, psychosocial, and structural factors that may influence the effectiveness of promoting the ABCs and other types of prevention interventions.

Among the key themes raised at the meeting were that although many existing programs already include ABC messages, it often remains unclear how these messages are understood by various audiences (e.g., youth, truck drivers), and how the different actors (e.g., schools, family, faith-based organizations) who 
communicate these messages affect their understanding. Participants felt that it is often unclear whether these messages are understood by different audiences to be compatible or contradictory, useful or not very relevant. And, it is also unclear how to best promote these behaviors, given the many contextual challenges, such as gender-based inequities, poverty, stigma, and other important environmental factors.

A collaborative study was developed and implemented in 2004-5 by Horizons and IMPACT to explore these and related themes. This report describes how working adults and in-school youth from two large areas, called divisions, in Nakuru District, Kenya, define and perceive the ABC terms and behaviors. It elucidates attitudes and norms around these behaviors, as well as barriers to and facilitators of the behaviors. And, it highlights the role of important actors in transmitting messages related to these behaviors. 


\section{Hgrizons}

\section{Methods}

\section{Study Overview}

The study was conducted in mid-2004 in two large geographical areas in the Nakuru district in Kenya: Naivasha and Molo. Both qualitative and quantitative methods were employed. Surveys addressing a number of HIV-related topics, including three open-ended questions on defining the ABCs, were administered to over 500 working adults at flower farms and almost 1,400 in-school youth (Table 1). These two groups were selected to represent a general youth and general adult population, so that findings would be relevant for a wide audience. Qualitative data via focus group discussions (FGDs) were also collected from in-school youth, flower farm workers, truckers, sex workers, and out-of-school youth. Those who participated in the survey did not participate in the FGDs. This report focuses on the data from in-school youth and flower farm workers.

Table 1 Total number of survey participants in study

\begin{tabular}{lccc}
\hline & Males & Females & Total \\
\hline $\begin{array}{l}\text { Flower farm workers (age } \\
\text { 18-49) }\end{array}$ & 274 & 264 & 538 \\
In-school (age 13-19) & 658 & 707 & 1,365 \\
Total & 938 & 971 & 1,903 \\
\hline
\end{tabular}

\section{Study site}

Two large communities (Naivasha and Molo) were selected to participate in the study because of their relative comparability. Both communities, locally called divisions, are in the district of Nakuru in Rift Valley Province, have a number of flower farms and surrounding schools, and have substantial trucking routes. Nakuru is the most densely populated district in Rift Valley Province. It is the provincial headquarters for the southern portion of the Rift Valley.

Naivasha is one of six divisions in Nakuru district. The trans-African highway passes through Naivasha town, which has a population of about 40,000. The highway connects Mombasa and Uganda. Naivasha, and particularly the South Lake region, is a horticultural zone famous for flower growing and export. For this reason, the town has attracted migrant workers from all over the country. Though a few farms provide housing to their staff, most do not and the workers reside in town. Therefore, there are many informal settlements in and around Naivasha.

Like Naivasha, the Molo division is in Nakuru district, and is largely an agricultural region. The region contains three main towns: Njoro, Elburgon, and Molo. Njoro town houses Egerton University, the main agricultural college in Kenya. The main staples of the Njoro/Molo region are maize, wheat, vegetables, 
and dairy, and there is a growing flower and horticultural industry. There is a large presence of smallscale farmers. One important difference between Naivasha and Molo is that Naivasha has a more mature flower farm industry, which employs a diverse migrant population from all over the country, while Molo residents and farm workers are largely from the local area. Like Naivasha, the Njoro/Molo area lies along the trans-African highway.

In Nakuru district, estimated adult HIV prevalence is 12.2 percent, based on surveillance data with pregnant women (UNAIDS, UNICEF, and WHO 2004). Data collected from voluntary counseling and testing (VCT) clients at the Molo sub-district hospital in 2004-2005 indicate an HIV prevalence of 11.8 percent overall, with 7 percent among male and 16.7 percent among female clients (Wambugu 2005). VCT data from the Naivasha sub-district hospital during the same period indicate an overall prevalence level of 12 percent, with 7.8 percent among male and 16.7 percent among female clients (Wambugu 2005).

\section{Sample and data collection}

The flower farm industry employs a large workforce in the Nakuru district; therefore, workers from this industry were chosen to represent an adult population in a workplace setting. In-school youth, from both primary and secondary schools, but mainly from primary schools, were chosen to represent the youth sample, since over 90 percent of youth attend primary school in Kenya.

The schools and flower farms were initially selected through systematic random sampling, drawn from a list provided by the Ministry of Health in both Naivasha and Molo. Of the 18 flower farms in Naivasha, 10 were randomly selected. Out of the original ten, four agreed to participate. An additional three were then randomly selected to participate, for a total of seven farms. The research team approached the managers of the flower farms, who then gave permission for the researchers to approach the adults working at the farm. Those adults who were available and willing to participate during the visit from the research team were included in the study. In Naivasha, 128 males and 117 females completed an informed consent form and the survey. Molo only had four flower farms, all of which participated in the study. A total of 146 males and 146 females completed the informed consent form and survey.

A systematic random sampling process, using probability proportionate to size, was conducted to select schools for the study. In Naivasha, 20 were chosen (16 primary and 4 secondary). After two schools refused to participate, one additional school was selected. In Molo, 13 schools were selected (nine primary, three secondary, and one both levels). Classes were selected to match the targeted age range for the study (13-19 years old), and included classes 5, 6, and 7 for primary schools, and 1, 2, and 3 for secondary schools. The students were then stratified into girls and boys and randomly selected from the schools, with assistance from the class registers. The stratification was implemented to ensure representation of both boys and girls. In Naivasha, 375 males and 342 females participated. In Molo, 329 males and 428 females participated. Students who were younger than 18 years of age were given parental consent forms for their parents to sign. The students who returned the parental consent forms and signed an individual consent form were asked to participate in the study. The great majority of students returned the consent forms and participated in the study; if consent forms were not returned, the student did not participate in the study, and new students were not selected to replace him or her. 


\section{Hgrizons}

Surveys were written in both English and Kiswahili, and were translated and back-translated by a team from the Nairobi-based NACPD, an organization with experience in this process. The survey was pretested at schools and flower farms not participating in the study.

Surveys were administered through an "interviewer-assisted" process. Surveys were self-administered, and interviewers were available on a one-on-one basis to answer questions or to read survey items if there were problems due to literacy levels. Lower literacy levels were found among the flower farm workers than among in-school youth; in general youth were able to complete the self-administered survey while flower farm workers required interviewer assistance.

Eight focus group discussions with in-school youth (five in Naivasha and three in Molo) and six with flower farm workers (four in Naivasha and two in Molo) were conducted and analyzed. The focus groups consisted of about eight participants each and lasted approximately two and a half hours. Focus group protocols were developed in English and translated into Kiswahili. Focus groups were conducted in Kiswahili, and the transcripts were first written in Kiswahili and then translated into English.

The in-school youth and flower farm workers who participated in the focus group discussions were conveniently selected. The in-school youth and flower farm workers were selected from the same locations as the survey sample, and a similar informed consent process was applied. Those who participated in the focus group discussions did not participate in the survey.

Data analysis and coding of key variables: For the purposes of determining baseline knowledge and opinions about the ABCs, as well as related risk and prevention behaviors, the samples were combined across the two sites-Molo and Naivasha-resulting in a total of 1,365 in-school youth and 538 flower farm workers. To confirm that the samples from the two sites were comparable, sociodemographic characteristics and other key responses of the flower farm workers and in-school youth were initially examined by study site. Substantial differences in key sociodemographic and HIV-related variables were not found between the sites (e.g., age, sex, HIV/AIDS knowledge, risk behaviors). However, the flower farm worker population in Naivasha was somewhat more educated than the Molo flower farm worker population.

For the analysis, frequencies, cross-tabulations, and chi-square tests were used to examine the relationships between key survey variables. Results are mainly reported for in-school youth and adults separately, and by sex within both of the groups. In-school youth were also split into younger youth (1314 years old) and older youth (15-19 years old), and analyzed separately. In addition, sexually experienced and non-experienced youth were analyzed separately. Results are shown separately for these categories when relevant. For the qualitative data, a content analysis was conducted. Common themes emerging from the content analysis are highlighted in the report.

Data on the clarity and understanding of the ABCs were obtained from both the survey and the focus group discussions. The survey included both close-ended and open-ended questions on the definitions and awareness of the ABCs in the context of HIV prevention. Respondents were asked whether they had heard of "abstinence," "being faithful," and “condom use” for HIV prevention. In addition to the closeended questions, survey participants were asked to write in their own definitions for the terms "abstinence,” "being faithful,” and “consistent condom use.” Responses were coded as: correct, partially correct, incorrect, respondent states that he/she does not know, and answer not a definition. The answers that were not definitions were further examined for themes raised, such as value judgments indicative of 
attitudes toward the behavior (e.g., condom use is immoral and is not effective; abstinence is good because it prevents AIDS).

Coding for "abstinence":

1. Abstinence responses were coded as "correct" if the respondent indicated not having sex at all or until marriage (e.g., "no sex," "not having sex until marriage").

2. Abstinence responses were coded as "incorrect" if the response was a definition and was clearly incorrect (e.g., "having sex with many people," or a different behavior such as "being faithful to one partner").

3. Abstinence responses were coded as "partially correct" if the respondent gave a definition indicative of delaying or waiting for sex for a period of time (e.g., "waiting to have sex until getting VCT results”), or gave multiple definitions where at least one was correct.

Coding for "being faithful":

1. Being faithful responses were coded as "correct" if the respondent indicated a definition focused on having only one sexual partner (e.g., "having one partner," "one sexual partner," "staying with one partner”).

2. Being faithful responses were coded as "incorrect" if the response was a definition but clearly did not mention having only one sexual partner (e.g., "being an honest and loyal person," "being kind to your partner," “depending on God for everything," "trusting one’s partner," "abstaining from sex").

3. Being faithful responses were coded as "partially correct" if the definition was not clear, but there was a suggestion of one sexual partner (e.g., "trusting one another-me and my partner alone," "being faithful to one partner"), or multiple responses where one was clearly correct.

Coding for "consistent condom use":

1. Consistent condom use responses were coded as "correct" if the definition focused on using condoms all the time or during each sexual act (e.g., "it's the use of condoms every time one has sex," "is using condoms everyday, every year, and every month without stopping”).

2. Consistent condom use responses were coded as "incorrect" if the definition was clearly wrong (e.g., "too much use of condoms") or a different behavior (e.g., "staying with one lover").

3. Consistent condom use responses were coded as "partially correct" when condom use was indicated but consistent use was not (e.g., "it means using condoms frequently," "using a condom every time you have sex with a partner whose HIV status you don’t know,” and “correct use of condoms”).

It is important to note that respondents were requested to supply a definition of "consistent condom use" as opposed to "condom use" alone, because it is only with consistent use that HIV infection can be prevented. However, as it is possible that the word consistent was a confusing term, the definition was considered partially correct if condom use during sex was mentioned at all.

\section{Sociodemographic Profile}

Approximately half of the flower farm workers were male and half were female, reflecting the typical ratio of male to female employees in the flower farms (Table 2). The mean age of the flower farm workers was 27.9 years, with a mean of 28.4 years for male workers and 27.3 years for female workers. About half of the in-school youth were male and half were female, reflecting the stratified sampling strategy. In-school youth were, on average, 14.9 years old, with a mean age for males and females, 


\section{Hgrizons}

respectively, of 15.1 years and 14.7 years. The great majority of youth and flower farm workers selfreported as Christian (Catholic or Protestant). According to national statistics of the general population, 45 percent are Protestant and 33 percent are Catholic, and the sample reflected similar prevalence. Sixty percent of the flower farm workers had at least some secondary education. Most of the in-school youth sample (81 percent) was currently attending primary school. Nineteen percent of in-school youth had been exposed to some secondary education. Regarding the work profile, the flower farm workers were selected to represent a working population, so all flower farm workers were currently employed. Seventeen percent of the in-school youth said they worked in some fashion to earn money.

Table 2 Sociodemographic profile of flower farm workers and in-school youth

\begin{tabular}{|c|c|c|}
\hline & $\begin{array}{l}\text { Flower farm workers } \\
\begin{array}{c}(18-49 \text { years }) \\
n=538\end{array}\end{array}$ & $\begin{array}{c}\text { In-school youth } \\
(13-19 \text { years) } \\
n=1365\end{array}$ \\
\hline \multicolumn{3}{|l|}{ Age } \\
\hline Mean age & $27.9 \mathrm{yrs}$ & $14.9 \mathrm{yrs}$ \\
\hline Male mean age & 28.4 yrs & 15.1 yrs \\
\hline \multirow[t]{2}{*}{ Female mean age } & $27.3 \mathrm{yrs}$ & $14.7 \mathrm{yrs}$ \\
\hline & $\%$ & $\%$ \\
\hline \multicolumn{3}{|l|}{ Sex } \\
\hline Male & 51 & 48 \\
\hline Female & 49 & 52 \\
\hline \multicolumn{3}{|l|}{ Religion } \\
\hline Catholic & 36 & 41 \\
\hline Protestant & 57 & 46 \\
\hline Muslim & 2 & 1 \\
\hline Traditional/other & 6 & 11 \\
\hline \multicolumn{3}{|l|}{ Education } \\
\hline Primary (incomplete/complete) & 39 & 81 \\
\hline Secondary (incomplete/complete) & 50 & 19 \\
\hline College/university & 10 & NA \\
\hline None & 1 & NA \\
\hline Currently have a job & $\sim 100$ & 17 \\
\hline
\end{tabular}

Almost 40 percent of flower farm workers were single and another 40 percent were married (Table 3). A higher proportion of male flower farm workers were married than their female counterparts. Almost onehalf (49 percent) of male flower farm workers were married compared to 29 percent of female workers. 
Table 3 Marital status of flower farm workers

\begin{tabular}{lccc}
\hline & $\begin{array}{c}\text { Male } \\
\mathbf{n = 2 6 1}\end{array}$ & $\begin{array}{c}\text { Female } \\
\mathbf{n = 2 5 1} \\
\mathbf{\%}\end{array}$ & $\begin{array}{c}\text { Total } \\
\mathbf{n = 5 2 4} \\
\mathbf{\%}\end{array}$ \\
\hline Single & 30 & 49 & 40 \\
Married & 49 & 29 & 40 \\
Polygamous & 8 & 8 & 8 \\
Cohabiting but not married & 5 & 4 & 5 \\
Regular partner but not cohabiting & 4 & 4 & 4 \\
Divorced/separated & 2 & 4 & 3 \\
Widowed & 1 & 2 & 1 \\
\hline
\end{tabular}

Note: $<5 \%$ missing data.

In-school youth were asked whether they had ever had a boyfriend or girlfriend, and about a third (32 percent) responded "yes." More males reported a girlfriend than females reported a boyfriend (39 percent vs. 25 percent, respectively). Of those in-school youth who reported having had a boy/girlfriend relationship, the maximum length of the relationship was one year, with the majority reporting a duration of three months or less. 


\section{Hgrizons}

\section{Results}

\section{HIV Awareness and Knowledge}

Both the flower farm workers and in-school youth reported a relatively high level of knowledge related to key HIV/AIDS topics (Table 4). Both groups had an almost universal awareness of the existence of HIV (> 95 percent). The great majority of respondents were aware that HIV is not transmitted via mosquito bites, and that a healthy looking person can be living with HIV infection. However, responses to questions about sexual transmission were somewhat less consistent. For example, about two-thirds (66 percent) of youth and 79 percent of flower farm workers indicated that using condoms correctly and consistently during sex is an effective method to prevent HIV transmission. Significantly fewer in-school youth than flower farm workers reported that condom use was protective $(\mathrm{p}<.05)$. A few differences by sex also emerged. Significantly more males reported that using condoms could protect a person from HIV infection compared to females $(\mathrm{p}<.05)$.

Table 4 HIV knowledge

\begin{tabular}{|c|c|c|c|c|c|c|}
\hline & \multicolumn{3}{|c|}{ Flower farm workers } & \multicolumn{3}{|c|}{ In-school youth } \\
\hline & $\begin{array}{c}\text { Male } \\
\%\end{array}$ & $\underset{\%}{\text { Female }}$ & $\begin{array}{l}\text { Total } \\
\text { farmers } \\
\%(n)\end{array}$ & $\begin{array}{c}\text { Male } \\
\%\end{array}$ & $\underset{\%}{\text { Female }}$ & $\begin{array}{l}\text { Total youth } \\
\%(n)\end{array}$ \\
\hline Ever heard of HIV & 98 & 96 & $\begin{array}{c}97 \\
(531)\end{array}$ & 98 & 96 & $\begin{array}{c}97 \\
(1,360)\end{array}$ \\
\hline $\begin{array}{l}\text { Agreed an individual can protect } \\
\text { him or herself from HIV by using a } \\
\text { condom correctly during every sex } \\
\text { act }\end{array}$ & 85 & 74 & $\begin{array}{c}79 \\
(499) \\
p<0.05\end{array}$ & 72 & 61 & $\begin{array}{l}66(1,271) \\
p<0.05\end{array}$ \\
\hline $\begin{array}{l}\text { Agreed an individual can protect } \\
\text { him or herself from HIV by not } \\
\text { having sex }\end{array}$ & 73 & 76 & $\begin{array}{c}74 \\
(475)\end{array}$ & 79 & 83 & $81(1,250)$ \\
\hline $\begin{array}{l}\text { Agreed that HIV is not transmitted } \\
\text { through a mosquito bite }\end{array}$ & 87 & 87 & $\begin{array}{c}87 \\
(504)\end{array}$ & 83 & 83 & $83(1,296)$ \\
\hline $\begin{array}{l}\text { Agreed that an individual who } \\
\text { looks healthy can also be infected } \\
\text { with HIV }\end{array}$ & 98 & 94 & $\begin{array}{c}93 \\
(512) \\
p<0.05\end{array}$ & 94 & 96 & $\begin{array}{c}95 \\
(1,316) \\
p<0.05\end{array}$ \\
\hline
\end{tabular}

NOTE: Sample size varies slightly due to missing data. Chi-squares were used to compare males and females.

When examining similarities and differences between responses of younger and older youth (13-14 year olds versus 15-19 year olds), the levels of HIV awareness and HIV-related knowledge were found to be similar. One difference was that older girls were more likely to report that individuals can acquire HIV 
from mosquito bites than younger girls (18 percent versus 11 percent; $\mathrm{p}<.05$ ). Sexually experienced and non-experienced youth had similar responses to these questions in general.

Qualitative data support the contention that HIV awareness and specific knowledge about HIV transmission and prevention, such as the fact that HIV is transmitted through sexual intercourse, is quite high. However, there were a few important misconceptions that were frequently reported. Among them were concerns about casual contact transmitting HIV, such as sharing clothes.

\section{Sexual Behavior}

Sexual risk behavior is of prime importance for understanding HIV risk and prevention. This section addresses sexual risk and prevention behaviors reported by flower farm workers and in-school youth. Among flower farm workers, 84 percent of males and 77 percent of females reported that they had had sexual intercourse at some time in the past, and about 70 percent of them were currently sexually active (defined as having sex during the last six months). Key findings on sexual behavior can be found in Table 5. Both male and female farm workers were similarly sexually experienced and sexually active.

Over a quarter (28 percent) of adult males and 14 percent of adult females reported ever having had sex with someone other than their primary partner. In addition, almost a quarter (22 percent) of males and 10 percent of females reported having had more than one partner during the past year. However, a substantial proportion of adult respondents also indicated that they had reduced their number of sex partners due to concern about HIV (62 percent of men and 49 percent of women).

The majority of flower farm workers — both male (76 percent) and female (55 percent) — had used a condom at some point in the past. Over half (61 percent) of sexually experienced flower farm workers reported that they used condoms with each of their sexual partners. And a quarter ( 25 percent) of the sexually experienced flower farm workers reported that they used condoms consistently (i.e., each time during their last 10 sexual events). 


\section{Hgrizons}

Table 5 Risk profile of sexually experienced flower farm workers

\begin{tabular}{lccc}
\hline & $\begin{array}{c}\text { Males } \\
\%\end{array}$ & $\begin{array}{c}\text { Females } \\
\%\end{array}$ & $\begin{array}{c}\text { Total } \\
\%\end{array}$ \\
\hline Sex in last 6 months & 71 & 70 & 71 \\
Ever used a condom & 76 & 55 & 67 \\
More than 1 partner in past year & 22 & 10 & 17 \\
Ever had sex with anyone other than girl/boyfriend/spouse & 28 & 14 & 21 \\
Used condom with each person they had sex with & 59 & 64 & 61 \\
Have reduced the number of sexual partners to avoid HIV & 62 & 49 & 56 \\
\hline
\end{tabular}

NOTE: Questions posed to sexually experienced males $(n=215)$ and sexually experienced females $(n=192)$. Sample sizes for each question vary due to missing data. No question missing more than $10 \%$ of data, except number of partners in past year (44\% missing) and whether used condom with every sexual partner (25\% missing).

A minority of youth reported sexual experience (Table 6). Specifically, 19 percent of 265 males aged 1314, 27 percent of 361 males aged 15-19, 4 percent of 338 females aged 13-14, and 10 percent of 337 females aged 15-19 reported sexual experience. These proportions are somewhat lower than other estimates, such as those found by the Demographic and Health Surveys (DHS 2003), which mainly represent out-of-school youth, but are consistent with the fact that in-school youth tend to be less sexually active than out-of-school youth.

Of those with sexual experience, about a quarter of those aged 13-14 and half of those aged 15-19 reported having had sex in the last six months. Overall, a higher proportion of male students reported sexual experience than female students, although sexually experienced female students were as likely to report current sexual activity as sexually experienced male students. The majority of those who had never had sex indicated that they were "waiting for marriage" as the main response as to why they had not had sex (51 percent of males aged 13-14; 65 percent of males aged 15-19; 54 percent of females aged 13-14; 67 percent of females aged 15-19).

Of the sexually experienced in-school youth, a minority had ever used a condom, with males having used them more often then females (42 percent vs. 27 percent) (Table 6). Only one of the 14 sexually experienced female youth aged 13-14 years had ever used a condom. 
Table 6 Risk profile of sexually experienced in-school youth (13-19 years old)

\begin{tabular}{l|cc|c}
\hline & $\begin{array}{c}\text { Males } \\
\%\end{array}$ & $\begin{array}{c}\text { Females } \\
\%\end{array}$ & $\begin{array}{c}\text { Total youth } \\
\%\end{array}$ \\
\hline Sex in last 6 months & 37 & 46 & 39 \\
Ever used a condom & 42 & 27 & 38 \\
Ever had sex with anyone other than & 21 & 15 & 20 \\
girl/boyfriend/spouse & & 41 & 40 \\
Used condom with each person they had sex with & 40 & 4 \\
\hline
\end{tabular}

NOTE: Questions posed to sexually experienced males $(n=150)$ and sexually experienced females $(n=47)$. Sample sizes for each question vary due to missing data. No question missing more than $10 \%$ of data, except whether used condom with every sexual partner (20\% missing).

\section{Awareness of the ABCs for HIV Prevention}

The great majority of both adult and youth respondents indicated that they had heard the ABC terms used in the context of HIV prevention. Specifically, 88 percent of adults and 84 percent of youth had heard of "abstinence" in this context, 97 percent of adults and 93 percent of youth had heard of "be faithful," and 95 percent of adults and 84 percent of youth had heard of "condom use." Youth were less likely to have heard of the ABCs for HIV prevention than adults ( $<$.05). Female flower farm workers and in-school girls were also less likely to have heard of condom use for HIV prevention than male flower farm workers and in-school boys $(\mathrm{p}<.05)$. Women were less likely to have heard of being faithful than men $(\mathrm{p}<.05)$. There were no significant differences between younger youth (aged 13-14) and older youth (aged 15-19) regarding whether they had heard of the ABCs for HIV prevention. There were also no significant differences between sexually experienced and non-experienced youth.

\section{Overall Clarity of the ABCs}

While the great majority had heard of the ABCs for HIV prevention, when asked to write a definition of the three terms, it became clear that a substantial proportion could not define these terms (Table 7). The responses were coded such that a correct response was a relatively strict definition of the termabstinence as no sex at all or until marriage, being faithful as sex with only one partner, consistent condom use as condom use during every sex act—and partially correct responses included much broader interpretations that implied some understanding of the terms. Responses that were not definitions, were missing key elements, or were unclear were common and coded separately (See Methodology section for a more detailed description of the coding).

"Abstinence" was the term that appeared to be the clearest; a higher proportion of both the adult sample (39 percent) and the youth sample (46 percent) supplied a correct definition of this term compared to their definitions of "being faithful" and "consistent condom use." The concept of "being faithful" in the context of HIV prevention was somewhat clear to the flower farm workers, as a majority responded with either a correct (35 percent) or partially correct (23 percent) definition of the term. In-school youth were very unclear about the definition of "being faithful," and 41 percent of youth answered this question 


\section{Hgrizons}

incorrectly. A very small proportion of both adults (17 percent) and youth (13 percent) supplied a correct definition of consistent condom use. A large proportion of youth (43 percent) chose to answer the question with an opinion about condom use, as opposed to a definition, and many adults (43 percent) chose not to answer the question at all.

Overall, adults had a better understanding of the terms than youth did. Few differences were seen between men's and women's responses. Male and female flower farm workers reported similar understandings of the ABCs, as did male and female in-school youth. In addition, no significant differences were found between younger youth (aged 13-14) and older youth (aged 15-19) nor sexually experienced compared with non-sexually experienced youth.

Table 7 Respondents' definitions of the ABC terms

\begin{tabular}{|c|c|c|c|c|c|c|}
\hline & \multicolumn{2}{|c|}{ Abstinence } & \multicolumn{2}{|c|}{ Be faithful } & \multicolumn{2}{|c|}{ Consistent condom use } \\
\hline & $\begin{array}{c}\begin{array}{c}\text { Flower } \\
\text { farm }\end{array} \\
\text { workers } \\
\mathbf{n}=538 \\
\%\end{array}$ & $\begin{array}{c}\text { In-school } \\
\text { youth } \\
n=1,365 \\
\%\end{array}$ & $\begin{array}{c}\text { Flower farm } \\
\text { workers } \\
\text { n= 537 } \\
\%\end{array}$ & $\begin{array}{c}\text { In-school } \\
\text { youth } \\
n=1,361 \\
\%\end{array}$ & $\begin{array}{c}\text { Flower farm } \\
\text { workers } \\
\text { n= } 537 \\
\%\end{array}$ & $\begin{array}{c}\text { In-school } \\
\text { youth } \\
n=1,360 \\
\%\end{array}$ \\
\hline Responded correctly & 39 & 46 & 35 & 23 & 17 & 13 \\
\hline $\begin{array}{l}\text { Responded partially } \\
\text { correct }\end{array}$ & 4 & 5 & 23 & 18 & 11 & 10 \\
\hline Responded incorrectly & 13 & 16 & 12 & 41 & 5 & 6 \\
\hline $\begin{array}{l}\text { Responded with "I } \\
\text { don't know" }\end{array}$ & 1 & 2 & 0 & 1 & 7 & 13 \\
\hline $\begin{array}{l}\text { Response was not a } \\
\text { definition }\end{array}$ & 12 & 21 & 4 & 12 & 18 & 43 \\
\hline Did not respond & 31 & 11 & 26 & 7 & 43 & 16 \\
\hline
\end{tabular}

When incorrect answers were supplied for the ABCs, certain themes repeated. It was common for respondents to confuse abstinence with another behavior (e.g., "being faithful to one partner") or to indicate the opposite of the definition (e.g., "having sex with many people"). Respondents often misunderstood and confused the term "being faithful" with other concepts and qualities, such as loyalty to a friend, being a trustworthy person, or trusting God. When defined in the context of a sexual relationship, it was commonly confused with trusting your partner, or having faith that your partner was faithful. Common incorrect definitions of consistent condom use included using condoms more than once, or confusing condom use with another behavior.

Some respondents did not supply a definition of abstinence, being faithful, or consistent condom use, and instead responded with an opinion or a statement about the behavior. This was particularly common for the condom use question; 18 percent of adult respondents and 43 percent of youth respondents did not provide a definition of consistent condom use. The difference is particularly pronounced after separating youth into primary and secondary school students. About half of the primary school students gave a non- 
definition to the question about consistent condom use compared to 24 percent of secondary students. Although some of the non-definition responses highlighted the positive aspects of HIV prevention, the majority indicated that condoms were ineffective for HIV prevention because they leaked or burst, or stated that using condoms was a "bad" or inappropriate behavior. Some youth advised their fellow youth not to use condoms in their responses to the open-ended question.

Fewer respondents overall provided an opinion or statement when asked to define abstinence (18 percent) or be faithful (9 percent). Most of the responses from both adults and youth displayed positive views about abstinence and being faithful when they did not provide a correct definition, such as "it is better to be faithful" or "good people abstain."

Although abstinence was the best-defined term of the ABCs in open-ended questions in the surveys, focus group discussion data highlighted some complexities. For example, abstinence was often defined with different endpoints by youth, as illustrated by this focus group discussion with primary school girls.

\section{Moderator: What do you understand by the word "abstinence"? \\ Respondent: Avoiding sex while still young. \\ Respondent: Avoiding sex while in primary and secondary schools. \\ Respondent: Avoiding sex.}

Adults tended to define abstinence as not having sex or stopping sexual activity. This broad understanding, which interchanges various definitions for abstinence and "delaying” sex, and primary and secondary abstinence, indicates that appropriate prevention messages need to take into account the varied definitions.

Respondents were asked to define "consistent condom use" in the context of HIV prevention. The condom use definition included the word consistent because only consistent use of condoms provides HIV protection in the long term, and the research team was interested in exploring the study population's understanding of that concept. Although responses indicated that condom use was understood as a barrier contraceptive, the word "consistent" may have been confusing since many responses indicated that consistent use was the need to use condoms "often" or the same condom multiple times. When the use of condoms was clearly mentioned, but consistent use was not described correctly, these responses were coded as partially correct. Qualitative data confirmed that it is often not clear to respondents that condoms need to be used consistently and correctly for HIV prevention.

\section{Attitudes Toward the ABCs}

Abstinence and being faithful were held in high regard by both groups, and were considered positively (Table 8), whether or not correct answers were given for the definitions. For example, 99 percent of adults and 98 percent of youth reported that being faithful is a good idea. Condom use was considered much less positively by youth; 36 percent who answered the question reported that condom use was a bad idea. But, many respondents did not answer the question, choosing to leave it blank. There were no significant differences in the responses to these questions when comparing males and females, younger youth and older youth, and sexually experienced and sexually inexperienced youth. These findings were supported by the focus group discussions in which all groups perceived abstinence and being faithful as positive behaviors, while condom use was perceived as largely negatively by youth and mixed by adults. 
Table 8 Percent of respondents who perceive each of the ABC behaviors as "good" (versus "bad")

\begin{tabular}{|c|c|c|c|c|c|c|}
\hline & \multicolumn{2}{|c|}{ Abstinence } & \multicolumn{2}{|c|}{ Being faithful } & \multicolumn{2}{|c|}{ Consistent condom use } \\
\hline & $\begin{array}{c}\text { In-school } \\
\text { youth } \\
n=1,096 \\
\%\end{array}$ & $\begin{array}{c}\text { Flower farm } \\
\text { workers } \\
\text { n= } 443 \\
\%\end{array}$ & $\begin{array}{c}\text { In-school } \\
\text { youth } \\
n=1,252 \\
\%\end{array}$ & $\begin{array}{c}\text { Flower farm } \\
\text { workers } \\
\text { n= 510 } \\
\%\end{array}$ & $\begin{array}{c}\text { In-school } \\
\text { youth } \\
n=457 \\
\%\end{array}$ & $\begin{array}{c}\text { Flower farm } \\
\text { workers } \\
\text { n = 277 } \\
\%\end{array}$ \\
\hline Good & 82 & 87 & 98 & 99 & 64 & 85 \\
\hline
\end{tabular}

Views about whether the ABCs can be implemented successfully were mixed. Both adult and youth survey respondents indicated that it was substantially easier to "be faithful" than it was to abstain from sex or to use condoms when having sex (Table 9). Significantly more in-school youth than flower farm workers reported that it was easy to abstain $(\mathrm{p}<.001)$. Significantly more adults than youth thought it was easy to use condoms ( $\mathrm{p}<.05)$, although once again the response rate was lower for the condom use question than the other questions. Significantly more female respondents reported that it was easy to abstain than male respondents $(\mathrm{p}<.01)$. No significant differences between groups were found for being faithful or condom use responses.

Table 9 Survey responses as to whether implementing the ABCs is "easy" or "hard," comparing in-school youth and flower farm workers

\begin{tabular}{|c|c|c|c|c|c|c|}
\hline & \multicolumn{2}{|c|}{ Abstinence* $^{*}$} & \multicolumn{2}{|c|}{ Be faithful } & \multicolumn{2}{|c|}{ Consistent condom use ${ }^{\star *}$} \\
\hline & $\begin{array}{c}\text { In-school } \\
\text { youth } \\
n=1,116 \\
\%\end{array}$ & $\begin{array}{c}\text { Flower farm } \\
\text { workers } \\
n=502 \\
\%\end{array}$ & $\begin{array}{c}\text { In-school } \\
\text { youth } \\
n=1,235 \\
\%\end{array}$ & $\begin{array}{c}\text { Flower farm } \\
\text { workers } \\
n=487 \\
\%\end{array}$ & $\begin{array}{c}\text { In-school } \\
\text { youth } \\
n=422 \\
\%\end{array}$ & $\begin{array}{c}\text { Flower farm } \\
\text { workers } \\
n=419 \\
\%\end{array}$ \\
\hline Easy & 72 & 61 & 89 & 90 & 58 & 65 \\
\hline
\end{tabular}

${ }^{\star} \mathrm{p}<.001,{ }^{\star \star} \mathrm{p}<.05 ; \mathrm{p}$-values are (Mantel-Haenzsel).

Yet, while survey responses indicated that it would be comparatively easy to be faithful, qualitative data highlighted many more difficulties. Various focus group participants indicated that they were skeptical of the possibility of implementing mutual monogamy. For example, when asked if married people in this area are faithful, a female youth participant replied, "No, they are never satisfied with their partners or spouses.”

The focus group data also highlighted that while abstinence was a socially supported behavior, it was not a feasible one. According to a flower farm worker, "It's [abstinence] an acceptable practice but it is not in practice. Let me say that out of 100 percent, truly speaking only two percent are abstaining." Older youth were also skeptical about the practice of abstinence, except for those who are very religious. 
Moderator: Is it [abstinence] a common practice?

Respondent: Not common.

Moderator: What category of people abstains?

Respondent: Some who are saved, the born again Christians.

Respondent: Those who have [sexual] self-control.

Moderator: What categories of people do not abstain?

Respondent: Pagans do not abstain.

Respondent: Adolescents in general.

Secondary school boys

When asked whether abstinence would prevent the spread of HIV/AIDS, a flower farm worker replied, "This cannot work. Abstinence cannot work for both men and women. More for the men. If you are a man you cannot live without doing sex.”

\section{Barriers to the Successful I mplementation of the ABCs}

\section{Mixed and conflicting messages}

Although respondents had heard messages about all three ABC behaviors and understood that they were intended for HIV prevention, the messages were sometimes contradictory and did not always fit well together. These contradictions led to internal conflicts and confusion.

Many youth explicitly stated that they received different messages from different sources, and from society in general, about how they should behave sexually. Youth predominantly spoke of issues related to abstinence, and whether or not to use condoms, as opposed to issues related to being faithful to one partner. In various examples, youth stated that there were both positive and negative community perceptions regarding abstinence and sexual activity.

Moderator: What are your cultural beliefs regarding abstinence?

Respondent: The community thinks that you are abnormal.

Respondent: The community regards one as holy and a role model.

Male in-school youth, secondary school

Youth also indicated that they received mixed messages regarding what was recommended and what was actually practiced. Various youth stated that they received many messages about needing to abstain, at the same time knowing that those providing the messages rarely practiced abstinence themselves.

Adults also spoke of confusing cultural messages; however, they were mainly related to being monogamous with one sexual partner versus having relationships with multiple partners. In the example below, a male flower farm worker clearly explains how he received both positive and negative messages from peers about monogamy.

Moderator: What would your friends think of you if you chose to be faithful to one partner?

Respondent: I have two opinions here. If the people were educated on issues concerning HIV/AIDS, they will say that I am leading a good life. But if they are not educated they will live 


\section{Hgrizons}

according to the earlier generations and they will say I am lost and I don't know how to approach women for sex.

Both adults and youth also raised the issue of hearing conflicting and confusing messages about condom use. Many respondents indicated being told that condoms may protect against HIV transmission, but also that they are ineffective.

Respondent: ...the people in the churches. They are very uneasy about using condoms.

Moderator: OK. What can we say about the clarity of the messages? What do you say, B?

Respondent: They say about condoms, that they are not 100\%. They can even bring them and educate you on them. They bring condoms and put in water, and then they try after about 5 minutes, the bottom starts becoming wet, implying that it is passing water through. So they show us that it is not $100 \%$.

Flower farm workers

\section{Fatalism}

Focus group discussions often uncovered an underlying sense of fatalism about HIV/AIDS among adults on the flower farms. Many discussion participants said that contracting HIV and dying from the disease is inevitable, and they pointed out the various other (often unlikely or incorrect) ways of transmitting the virus. These comments were sometimes used to justify continuing with risky behaviors, as illustrated by the quotes below from flower farm workers.

Even if I stop alone, and in Kenya we are 30 million, that will be a waste of time. This is because others will be doing it and people will continue getting infected.

It will not help. Even if people abstained, sex is not the only way one can get HIV/AIDS. For instance, I can abstain. I have not even married, and I have not had sex with anybody and then I get infected through ironed sheets or injections in hospitals, I will be having the virus and I will die like anyone else.

\section{Desire to have children}

The desire to have children was important to many participants, both men and women. Women and girls described how the desire to have children is one reason why abstinence or using condoms is impossible for them to implement.

Moderator: How is one regarded culturally if he/she decides to "delay sex?"

Respondent: Regarded as that one who does not give birth to children.

Flower farm worker

Moderator: Is it [using condoms] possible?

Respondent. It will be possible if you are not married. Again, you cannot use condoms always. If you have not gotten the children that you want.

Flower farm worker 
In-school girls also talked about how the community would laugh at a childless woman and say that she is bewitched.

\section{Gender-based power dynamics/gender norms}

A frequently raised barrier to the $\mathrm{ABC}$ behaviors was gender dynamics. Norms about socially appropriate behaviors for men and women were discussed in many focus groups and highlighted as barriers. For example, men were understood to need multiple sexual partners, since having multiple partners is perceived as enhancing one's manhood. Gender-based power imbalances and threats of violence that lead to women's inability to decide when or if to have sex, as well as to influence their husbands' sexual behaviors, were also discussed at various points.

The majority of in-school youth in the focus groups voiced how difficult it is for males to be sexually faithful to one partner. Respondents reported that having multiple partners impresses other young men and demonstrates young men's virility.

Moderator: Why is it so difficult for the youth to be faithful?

Respondent: To prove manhood — by having two girls.

Respondent: To gain fame among the fellows.

Male in-school youth, secondary school

Flower farm workers, both men and women, also reported that men needed more than one sexual partner. According to one male focus group participant:

For women it [being faithful] is possible but for men it is not possible. They say "you cannot eat sukuma everyday" you must change your diet. They have to eat chapatti. You know they say that the wife is githeri (beans and maize) and gacungwa (girlfriend) is chappati. So he will say that he must change diet because his teeth will start aching because of eating githeri daily.

Participants in one focus group explained that men were more likely than women to be unfaithful, because if a woman tried to do the same, she would face violence from her partner. As noted by one participant, "You know that a woman would fear to do so because if he knows, he will beat her."

Abstinence within marriage was seen as possible by some respondents and abnormal by others. Among those who thought abstinence was possible, many flower farm workers believed that a woman could refrain from sex but a man could not. One female flower farm worker commented, "I can choose to avoid sex but my mzee [husband] cannot." Another pointed out, "You know we can agree to abstain with my husband, but once he goes out he will do it and bring AIDS.”

Condom use was reported as desired by many married women, but they indicated that women could not negotiate condom use with their husbands. According to one flower farm worker, "You know it is not easy for a woman to go for condoms at the shopping center. And again if you happen to tell the man to put on a condom, he will knock off your teeth and beat thoroughly.” 


\section{Hgrizons}

\section{Transactional, coerced, and forced sex}

Transactional, coerced, and forced sex are barriers to abstinence, faithfulness, and condom use, as mentioned by focus group participants. They also mentioned that poverty forces many individuals, particularly women and girls, to engage in unwanted transactional sex. According to one flower farm worker, "When children start crying and maybe the husband has neglected her together with the children, she could find herself going for sex outside. She will say, 'Let me suffer so long as the children eat."' Many respondents discussed transactional sex as a way to earn an income, or to supplement an existing income.

Rape and forced or coerced sex were commonly mentioned issues that pose insurmountable barriers to implementing the ABCs. Both flower farm workers and in-school youth discussed situations where adults coerce adolescents, particularly young girls, into sexual relationships with older men ("sugar daddies") in exchange for money. Other participants suggested that parents force the young girls into sexual relationships with these men in an effort to supplement the household income. Forced sex was reported to take place in the community and in key institutions such as schools.

\section{Perception that sexuality cannot be controlled by the individual}

A substantial proportion of survey respondents indicated that it would be "easy" as opposed to "hard" to abstain from sex. However, many participants also highlighted the difficulties experienced when attempting to abstain from sex. Many provided responses that indicated a belief that sexual behavior is beyond the control of the individual.

Some individuals pointed out additional factors that lead to a loss of control over sexual behavior, such as exposure to pornographic movies and printed material, or certain types of foods. According to one flower farm worker, "Our bodies have a lot of heat. We cannot stay without doing sex." These issues emerged in both the open-ended questions in the survey, as well as the focus group discussions.

In addition, many participants placed the blame for limited sexual control on others. Adult men and male youth most often mentioned the way women dress and act as the reasons why they were unable to control themselves sexually. As noted by one male in-school youth, "The way girls dress make if difficult to abstain.”

Respondents indicated that men have a harder time controlling their sexual impulses than women. Some respondents mentioned that the only way men could practice abstinence would be to totally separate women and men.

\section{Physical effects of abstinence and faithfulness}

The idea that abstaining and being faithful has negative physical repercussions, particularly for men, was discussed in various contexts during the focus groups, mainly among adults. Back pain, joint pain, greater susceptibility to malaria, and an inability to urinate were a few of the many ailments ascribed to abstaining from sex and having only one sexual partner. 
Sometimes we hear there is a disease that affects men who do not have sex. That we have heard, that so and so is suffering from a certain illness for not having a wife.

It involves one's inability to pass urine. The urethra closes such that it becomes very difficult to pass urine. It affects the elderly men, whose wives have become sexually inactive, those are the ones that suffer Muthiori. You find that wherever a man's wife has become too old to do sex, the man suffers that disease, Muthiori.

Several respondents also mentioned that doctors commonly reinforce these misconceptions.

\section{Other barriers to abstinence and faithfulness}

There were several additional barriers that were named infrequently during focus group discussions but were noteworthy. Natural adolescent curiosity to learn about and experience sex was mentioned during one discussion with secondary school boys. In a separate discussion, secondary school boys highlighted another issue that is often overlooked when considering sexual behavior among youth: sex as an expression of emotions or love. According to one male youth, "There are some people who want to have sex just because they want to enhance their love-if you want to show someone that you really love her!"

\section{Condoms are ineffective and/or damaging}

Many focus group participants expressed concerns regarding the effectiveness of condoms in preventing the spread of HIV. More than two-thirds of adult survey respondents (70 percent) and youth survey respondents (71 percent) indicated that condoms "may be ineffective." One of the most commonly cited examples was that condoms have holes in them or that they can burst inside of a person. It was evident from the open-ended responses in the survey that numerous individuals thought that condoms would therefore not prevent the spread of the virus, as seen in the examples below:

I understand that there are faulty condoms with holes throughout which viruses can pass and thus cause infection.

Condom can get torn when having sex.

If you use a condom for half an hour it's bad because it will get torn when inside.

Condom use is not good because it can burst and pass water.

Focus group participants also expressed concerns that condoms actually spread HIV. Some respondents indicated that use of condoms could be harmful or damaging to one's health in other ways. This information is reportedly distributed on the radio or by respected individuals, as evidenced by these comments from female in-school youth:

Moderator: What is your opinion of condom use?

Respondent: The radio says they have virus. 


\title{
Hgrizons
}

Moderator: Is it so?
Respondent: We are told it has small holes that can allow the virus to go through.

\section{Condoms can be sabotaged}

The intentional ripping and tearing, or sabotaging, of condoms is another example participants gave to support the lack of interest in condoms. Women expressed concerns about their partners sabotaging the condoms and men discussed wanting to sabotage the condoms in an effort to enhance the sexual experience. According to one male flower farm worker:

There are some other women who say that, "it's a must that we use condoms-if not, let the whole thing go." When I see that, as a man I conclude that this is the one who does not have AIDS, [and] that is why she is saying that she must use condoms. That is why I must look for mbino, a way of going inside without a condom. I am not lying. If it means tearing the condom with my hands, I will.

\section{Using condoms reduces pleasure}

The reduction of pleasure was repeatedly discussed by both male and female respondents as being a barrier to condom use. In addition to reducing sexual pleasure, adults also discussed physical discomfort associated with condom use.

\author{
Moderator: Why are people not using condoms. Let us start with the men, what do \\ they say? \\ Respondent: They don't get the pleasure. \\ Moderator: What do the women say? \\ Respondent: Some say that condom is made of some chemicals that when it stays in \\ the vagina for long, they start itching.
}

\section{Using condoms implies a lack of trust}

Many adults, both male and female, expressed concerns regarding the lack of trust that is implied by asking a partner to use a condom. The trust issues were different for men and women and varied according to the type of relationship. Male respondents reported that consistent condom use was not possible because they could not or would not use condoms with their wives or with women with whom they had a trusting relationship. Several respondents said that condoms would not be used if you intended to marry the partner, the relationship was a trusting one, or you wanted to gain someone's trust. When researchers asked adult survey respondents about why they were not using condoms, the majority (65 percent) answered that it was because they trusted their partners not to put them at risk of infection. For women, a commonly cited issue related to discussing condom use was the fear of physical repercussions should their partner suspect infidelity. 


\section{People who use condoms are "bad"}

A number of focus group respondents indicated that people who use condoms were considered bad or naughty. Other respondents expressed concerns over being regarded as immoral by partners.

Moderator: What do people say about those who use condoms?

Respondent: One is regarded as naughty and immoral.

Respondent: They say that one loves sex in the negative sense.

Male in-school youth, secondary school

\section{Others barriers to condom use}

There were various barriers to condom use that were mentioned only once or infrequently during the focus groups. They include fearing that the condoms being sold were used previously, that alcohol and substance abuse leads people to "forget" to use condoms, that condoms were difficult to use, and that feeling healthy led to feeling you do not need to use a condom.

\section{Facilitators for the Successful I mplementation of the ABCs}

\section{Education, awareness, and communication}

When asked about ways to increase the practices of abstinence, faithfulness, and using condoms within their communities, participants encouraged open communication between partners. Focus group participants also mentioned increasing awareness about HIV through education. Some participants mentioned that abstinence was possible for them because they were educated and informed about how people died of AIDS. As one person said, "It is possible to delay if people are educated about it." Some adult respondents encouraged interpersonal education or media messages.

Just like you have called us today, you need to call for a meeting, train us on the importance of being faithful as well as the dangers of a man going out and also for a woman to move out. We need to be taught on why we should always work together with our men. We need also to be trained on decision-making and the importance of being open to each other in whatever we do.

Call them for a seminar to educate them about the importance of using condoms because there are others who just hear about condoms but they don't know to use them. So they should be shown how to use them.

In fact, there was a relationship between level of education and clarity about the ABCs. Those in secondary school (57 percent) were more likely to define abstinence correctly than primary school students (44 percent). The higher the level of education that the flower farm workers had, the more likely they were to correctly define abstinence. 


\section{Hgrizons}

\section{Abstinence and faithfulness are socially acceptable behaviors}

When asked about abstinence and faithfulness during the focus group discussions as well as in the survey, the majority of participants responded favorably. Various statements were given about how abstinence and monogamy are socially acceptable behaviors, which would facilitate the promotion of these behaviors. The open-ended responses in the survey, asking about a definition of abstinence and being faithful in the context of HIV prevention, included a number of opinions about these behaviors that implied support for them. For example: "it is good to abstain," and "[faithfulness] is someone with good behavior."

\section{Personal religious and spiritual beliefs}

Many focus group participants, particularly adult flower farm workers, mentioned the role of religion and spirituality in guiding their own sexual practices. Some of these individuals spoke favorably of the potential role of religion and spirituality in encouraging abstinence and faithfulness. According to one flower farm worker:

Involve yourself with the things of God. Because in church we are taught that sex is nature but.... Nature may make your body demand for sex. But there is that which God has given you to prevent it.

While the role of religion was usually considered positive when attempting to stay abstinent or monogamous with one partner, flower farm workers in Molo pointed out that sometimes men pretend they are following church doctrine to avoid using condoms with a potential partner.

\section{Not thinking or talking about sex}

Some respondents felt that by avoiding sexual thoughts and ceasing to talk about sex, an individual would be in a better position to practice abstinence and faithfulness. Several male focus groups participants advised staying away from women who are involved in sex or pornography to avoid thinking about sex. Female respondents felt that women could avoid being tempted by sex by thinking of the welfare of their children. According to one female flower farm worker in Naivasha, "You can persevere without sex when you think of your own life and that of your children.”

\section{Planning for regular encounters with partners}

Flower farm workers reported several strategies that could help individuals be faithful. They suggested that making plans for the next sexual encounter with their spouse or boyfriend/girlfriend might make faithfulness more feasible. In particular, women suggested that couples who are separated by their jobs should make plans for regular meetings so that neither partner is tempted to have sex with someone else. According to one flower farm worker: 
Also, if it is your partner, you should ensure that you have time together so that you educate one another always. Because if you are my partner and you are in Naivasha and I am here and we stay for 6 months before seeing each other, to me, one of us will be tempted. But at least if you are meeting regularly, you are educating one another.

\section{Condoms protect from HIV and other unwanted outcomes}

Participants in the focus group discussions and surveys expressed a desire to protect themselves and their partners from HIV. Many, particularly adults, spoke of the importance of condom use to reduce risk. A number of open-ended responses from the surveys support the idea that many study participants are aware of the importance of using condoms for HIV prevention and unwanted pregnancy.

Condom use is advantageous because if one of you has the virus, he/she will not spread it to his/her partner.

You must use condom when having sex to avoid AIDS.

When you use a condom you will not get AIDS or you will not make a woman pregnant.

We should use condom every time we have sex. To protect yourself not to get HIV/AIDS.

One focus group of female flower farm workers reported ambivalent feelings about having their husbands suggest condom use, as this could imply infidelity. However, the women discussed the fact that it would also imply that he was concerned about his personal health and safety and the safety of their family. The women explained how they would be secretly pleased by their partners' desire to protect them from HIV infection.

Respondent: In my opinion, if I get him with a condom, I will be rough on him but inwardly I will be happy to learn that my husband cares about our life. I will know that he takes care of himself out there.

All: $\quad$ Agree.

Respondent: I mean that I will be harsh with him but in my heart I will be happy because I will know that we are safe from the disease since he knows the protection.

\section{Sources of HI V-related I nformation}

\section{Radio is an important source of information but not the preferred method.}

Both in-school youth and adult flower farm workers reported that the radio was a principal source of HIV prevention information (Table 10). Both younger (aged 13-14) and older youth (aged 15-19), as well as sexually experienced and non-experienced youth (not shown) reported the radio as an important source. Television was also an important source of information for in-school youth, but not for adult flower farm workers. The church was the least frequently mentioned source of information about HIV prevention by both groups. 


\section{Hgrizons}

Despite its prevalence as a source of information, however, the radio was not the preferred method of receiving HIV information for either youth or adults, according to focus group participants. The flower farm workers explained that everyone had a radio and that information was explained well on radio shows. Nevertheless, the adults preferred getting information through interpersonal seminars. Several people mentioned seminars held at their workplace, the hospital, or when community-based organizations presented special seminars at churches or other places. Participants wanted more seminars and praised past presentations at their workplace, mentioning that it was easier to learn when one could see the speaker face-to-face. According to one flower farm worker:

On my part, I would say that for us flower farm workers, we would prefer that you people organize seminars for us. People should be trained, could be in a hall, and in addition, you could also come even with people living with HIV/AIDS, so that we can see them and know the truth about AIDS. That way each person will get the right information. Some time back, we used to have seminars, which I think were better than even the radio because people were called from various departments in the farm, trained the whole day, and people took the messages very seriously.

An additional finding concerns the exposure of sexually experienced youth to HIV-related information from health workers (not shown). While 30 percent of older, sexually experienced youth (aged 15-19) reported having received information about the ABCs from health workers, only 13 percent of younger, sexually experienced youth (aged 13-14) reported the same.

Table 10 Most common sources of information on ABC messages for adults and youth

\begin{tabular}{|c|c|c|c|c|c|c|c|c|c|}
\hline & \multicolumn{3}{|c|}{ Flower farm workers } & \multicolumn{6}{|c|}{ In-school youth } \\
\hline & $\begin{array}{l}\text { Abstinence } \\
\qquad n=537\end{array}$ & $\begin{array}{c}\mathrm{Be} \\
\text { faithful }\end{array}$ & $\begin{array}{c}\text { Condoms } \\
n=537\end{array}$ & Absti & ence & $B e f$ & thful & $\begin{array}{l}\text { Con } \\
\mathrm{n}=\end{array}$ & $\begin{array}{l}\text { oms } \\
474\end{array}$ \\
\hline & & $\%$ & & $\begin{array}{c}13-14 \\
n=626\end{array}$ & $\begin{array}{c}15-19 \\
n=739\end{array}$ & $\begin{array}{c}13-14 \\
n=626\end{array}$ & $\begin{array}{c}15-19 \\
n=739\end{array}$ & $\begin{array}{c}13-14 \\
n=626\end{array}$ & $\begin{array}{l}15-19 \\
n=739\end{array}$ \\
\hline Radio & 53 & 62 & 73 & 59 & 67 & 41 & 49 & 65 & 69 \\
\hline $\begin{array}{l}\text { Health } \\
\text { workers }\end{array}$ & 27 & 31 & 33 & 34 & 35 & 20 & 19 & 22 & 23 \\
\hline Television & 30 & 35 & 48 & 62 & 58 & 42 & 37 & 60 & 55 \\
\hline $\begin{array}{l}\text { News- } \\
\text { paper/ } \\
\text { magazine }\end{array}$ & 26 & 28 & 34 & 59 & 53 & 35 & 36 & 47 & 47 \\
\hline $\begin{array}{l}\text { Church/ } \\
\text { mosque }\end{array}$ & 12 & 22 & 0 & 4 & 4 & 18 & 23 & 3 & 4 \\
\hline
\end{tabular}

Note: Multiple answers possible. 
Both adults and youth discuss the ABCs with others, most commonly with their friends, although friends may not be considered reliable.

A majority of both flower farm workers and in-school youth reported that they had spoken with others about each of the ABC behaviors in the past six months (Table 11). About three-quarters of adult flower farm workers had spoken about all three behaviors: abstinence, being faithful, and condoms. While over three-quarters of in-school youth indicated that they had spoken with someone about abstinence and being faithful, a substantially smaller proportion—about one half—indicated the same about condoms.

\section{Table 11 Who respondents communicate with about the ABCs}

Have you talked with anyone about this topic in the last 6 months?

\begin{tabular}{|c|c|c|c|c|c|c|c|c|c|}
\hline & \multicolumn{3}{|c|}{ Flower farm workers } & \multicolumn{6}{|c|}{ In-school youth } \\
\hline & \multirow{2}{*}{$\begin{array}{c}\text { Abstinence } \\
\text { n= } 469 \\
\%\end{array}$} & \multirow{2}{*}{$\begin{array}{c}\text { Be faithful } \\
\text { n = } 517 \\
\%\end{array}$} & \multirow{2}{*}{$\begin{array}{l}\text { Condoms } \\
\begin{array}{c}\text { n = } 492 \\
\%\end{array}\end{array}$} & \multicolumn{2}{|c|}{ Abstinence } & \multicolumn{2}{|c|}{ Be faithful } & \multicolumn{2}{|c|}{ Condoms } \\
\hline & & & & $\begin{array}{c}13-14 \\
n=740 \\
\%\end{array}$ & $\begin{array}{c}15-19 \\
n=746 \\
\%\end{array}$ & $\begin{array}{c}13-14 \\
n=740 \\
\%\end{array}$ & $\begin{array}{c}15-19 \\
n=746 \\
\%\end{array}$ & $\begin{array}{c}13-14 \\
n=740 \\
\%\end{array}$ & $\begin{array}{c}15-19 \\
n=746 \\
\%\end{array}$ \\
\hline $\begin{array}{l}\text { Have talked to } \\
\text { someone }\end{array}$ & 78 & 85 & 72 & 74 & 75 & 86 & 83 & 55 & 58 \\
\hline Talked to... & $\begin{array}{c}\mathbf{n}=367 \\
\%\end{array}$ & $\begin{array}{c}n=439 \\
\%\end{array}$ & $\begin{array}{c}n=355 \\
\%\end{array}$ & $\begin{array}{c}n=382 \\
\%\end{array}$ & $\begin{array}{c}n=459 \\
\%\end{array}$ & $\begin{array}{c}n=493 \\
\%\end{array}$ & $\begin{array}{c}n=553 \\
\%\end{array}$ & $\begin{array}{c}n=338 \\
\%\end{array}$ & $\begin{array}{c}n=422 \\
\%\end{array}$ \\
\hline Friend & 71 & 72 & 74 & 79 & 81 & 82 & 81 & 81 & 82 \\
\hline Neighbor & 22 & 30 & 19 & 28 & 29 & 29 & 28 & 15 & 10 \\
\hline $\begin{array}{l}\text { Spouse/ } \\
\text { partner or } \\
\text { girl/boyfriend }\end{array}$ & 27 & 37 & 39 & 28 & 36 & 26 & 36 & 30 & 48 \\
\hline Family member & 32 & 42 & 30 & 44 & 45 & 44 & 45 & 44 & 33 \\
\hline Teacher & 7 & 7 & 8 & 59 & 52 & 55 & 48 & 65 & 50 \\
\hline Church/clergy & 13 & 13 & 10 & 14 & 17 & 15 & 20 & 7 & 6 \\
\hline $\begin{array}{l}\text { Community } \\
\text { leader }\end{array}$ & 7 & 7 & 9 & 9 & 10 & 9 & 7 & 5 & 7 \\
\hline Doctor/nurse & 20 & 17 & 26 & 23 & 17 & 21 & 14 & 27 & 19 \\
\hline Other & 1 & 1 & 1 & 1 & 0 & 0 & 1 & 0 & 1 \\
\hline
\end{tabular}

NOTE: Table does not include those who have not heard of the ABCs, nor missing values. 


\section{Hgrizons}

Among the flower farm workers who spoke with someone about the ABCs, they reported discussing the behaviors with their friends primarily, followed by family members and spouses/partners. The focus group discussions also supported the fact that the flower farm workers talk to their friends about HIV. However, as one focus group participant describes, they may not find the information that they receive from their friends as reliable as other sources. "Friends are the ones who I can say don't have full understanding about what they are saying because you can be told something and when you probe further, you'll realize that they don't know."

Youth also most commonly reported speaking with friends about the ABCs, followed by teachers and family members. Of note is that youth spoke less often about condoms and more about abstinence and being faithful with family members, and more often about condoms and less about abstinence and being faithful with teachers. When in-school youth spoke with friends, they spoke equally as often about condoms as the other two behaviors.

Focus group data support the survey finding that youth receive HIV information from multiple sources, including friends, teachers, parents, and the media. However, in-school youth mentioned teachers/schools, doctors, and parents as their most trusted sources of information, as opposed to the media or friends. Primary school girls indicated that parents were the most reliable source of information. 


\section{Discussion and Recommendations}

The ABCs are increasingly becoming the basis of HIV prevention programming in many contexts. Therefore, it is important to understand how different audiences understand and view each of the recommended behaviors - abstain from sex, be faithful to one sexual partner, and use condoms consistently_as well as to elucidate barriers to and facilitators of these behaviors. Findings from this study with working adults and in-school youth in Kenya indicate that the vast majority of the study groups had heard of each of the ABC terms in the context of HIV prevention. However, there was a good deal of variation regarding how they interpreted the terms and what they believed about the behaviors. There also were reported inconsistencies in what different communication sources said about the importance and relevance of each of the behaviors in relation to HIV prevention. And, a number of challenges were raised that questioned whether it was possible to implement some or any of the behaviors, especially for women and girls, as well as some suggestions from participants regarding what factors inhibit or assist them when attempting to practice the behaviors.

When asked to define the ABC terms, abstinence was the most correctly defined term. Yet there was still a substantial proportion of respondents who did not or could not give a correct definition. Both adults and in-school youth often confused the being faithful term with other concepts or qualities, such as loyalty to another person, or being faithful to God. And, when respondents defined it in the context of a sexual relationship, it was commonly confused with trusting your partner, or having faith that your partner was faithful. This confusion is quite important, since reaching the goal of being faithful to one sexual partner would likely entail open communication and negotiation over the issue, and not simply relying on trust that one's partner is maintaining the behavior. Both groups also had a difficult time correctly defining consistent condom use. These findings highlight the need for clarification of what is meant by these terms, particularly being faithful to a sexual partner in the context of HIV prevention. It is important for programs to utilize terminology that is locally appropriate and clear. This is not a new conclusion in the world of HIV programming, but it bears repeating, given the findings from the study. Furthermore, it is important not to get caught in generalities and vague messages, as commonly takes place when messages are created for a "general" population, and instead to tailor the messages to the audience. To address faithfulness in a relationship for sexually active adults, for example, explicit and specific language is needed.

Study findings also revealed that while the radio is a main source of HIV-related information for both the flower farm workers and in-school youth, interpersonal and interactive sources were preferred. This was because of their ability to permit exchange and dialogue. So, including these channels of information would be important for programs in this context. Respondents also indicated that they most often spoke to friends about the ABCs, but that friends were not necessarily the most reliable or trusted source of information. Youth peer education programs that focus on ensuring the reliability of information from peers, combined with more traditional sources of health information, such as schools and clinics, could be important communication channels in this context.

Whether or not their definitions were correct, most respondents were strongly supportive of the AB behaviors, particularly abstinence for youth and being faithful for adults. Attitudes toward condom use were mixed but largely negative-youth tended to report negative opinions about condoms, and the opinions of working adults were more positive but still mixed. Some adults had negative opinions about 


\section{Hgrizons}

condoms, such as that they caused conflict when raised in a relationship, as it implied a lack of faithfulness, or that they were ineffective, and others highlighted the benefit of HIV or pregnancy prevention. Many adults left the question asking participants to define "consistent condom use" blank, suggesting that they may have been uncomfortable answering. It is also likely that the word "consistent" was a difficult word to define, but, it was also apparent from this open-ended question that it was unclear to the respondents how often or regularly condoms would need to be used to be most effective. And both in-school youth and working adults gave examples of how they were "taught" that condoms were either inferior to other options, or that they were completely ineffective.

To implement a balanced ABC program, all components should be discussed and offered as options, so these negative views about and discomfort with condoms need to be examined and addressed. Debates about the appropriateness and effectiveness of condom use have a long-standing history in the Kenyan context; it is clear that study respondents have received inconsistent and negative messages about condoms, especially in-school youth. Negative attitudes were likely reflected in the reported limited use of condoms. It is obviously a challenge in this context to openly discuss condoms and highlight when it is appropriate to use them-given existing messages that condoms are not effective and are used by immoral people—but a frank and open dialogue is needed.

Surprisingly, there were minimal differences found between younger (aged 13-14) and older (aged 1519) in-school youth regarding their HIV knowledge, their understanding of the ABC behaviors, and their attitudes toward the behaviors. Nor were there substantial differences between sexually experienced and non-experienced in-school youth. This may be due to the fact that the in-school population is already quite self-selected, and differences would be seen when compared to out-of-school youth. In fact, in other focus groups with out-of-school youth (not reported here) more risk behavior was reported, as well as more skepticism toward abstinence and being faithful, and more positive views toward condom use. Since quantitative information was not available from this group, they were not a focus of the analysis and report. Nor were there very substantial differences between men and women on HIV knowledge, clarity of the ABCs, and attitudes toward the ABCs.

Even though abstinence and being faithful were considered very positive behaviors by both adults and youth, a number of barriers were raised that indicated that practicing the behaviors was difficult or impossible given the existing circumstances. Respondents from varied backgrounds-men and women, girls and boys-mentioned the need for sex and a lack of ability to control sexuality. A sense of fatalism about HIV, where HIV was perceived to be so common that there was no way to avoid infection nor any need to engage in risk reduction behaviors such as mutual monogamy, was also reported periodically. Other respondents highlighted the potential physical damage that would be caused if a person abstained from sex. In addition to these issues, a number of structural issues-particularly those affecting women and girls-were raised as barriers to abstinence and being faithful to one sexual partner. These included gender-based power dynamics inhibiting women's ability to negotiate issues related to sexual behaviorincluding whether to have sex or not (i.e., rape), gender norms related to men needing multiple sexual partners, and the role of poverty in necessitating transactional sex. While there was some agreement between men and women about the main barriers to and facilitators of the ABC behaviors, there were also important differences, with men often mentioning that women's suggestive behavior or clothing were to blame for certain behaviors on the part of men, and women more often raising concerns about coerced or forced sex. 
Many barriers to using condoms were reported as well. They included women's inability to successfully negotiate condom use with an unwilling partner, perceptions that condom were ineffective or actually dangerous, and that initiating discussions about condom use creates conflict in relationships, as it raises the possibility that one partner had been unfaithful.

Focus group participants were also asked for suggestions regarding how to successfully implement each of the ABC behaviors, either from their own experience or what they would recommend to others. Many respondents recommended open communication between partners, and additional education and information to help them prompt and engage in discussions. A few creative suggestions also emerged, some of which are easier to implement than others. For example, one respondent suggested planning for sexual encounters with spouses or partners, to try to reduce incentives to develop outside partnerships. This strategy would be quite complicated for mobile or migrant individuals, but some couples may be able to implement this suggestion.

These findings about each of the ABC behaviors have multiple implications. On the one hand, there is potential for programs to build upon the strong support for abstinence and sexual monogamy, as the program messages would be consistent with widely accepted norms. And, there is potential for programs to counteract inaccurate messages about the ineffectiveness of condoms. On the other hand, the various barriers described highlight the need to combine these activities with other types of interventions that would permit individuals to enact these behaviors, if they choose to do so. In particular, the barriers for women and girls related to transactional, coerced, and forced sex must be actively and directly taken into account for ABC-focused programs to be successful. Relevant interventions could range from clinicbased gender-based violence reduction programs, to microcredit programs that enable women to find and develop alternative ways to generate income, to school-based programs promoting safety for girls in school. Furthermore, counter-productive perceptions about sexuality and HIV, such as the widespread belief that it is impossible for men to control their sexual behavior, and the perception that HIV is so widespread that it is impossible to avoid, also need to be directly addressed.

Most if not all of these barriers to HIV prevention behaviors have been reported in other contexts (e.g., Parker, Easton, and Klein 2000), so this information is not new. These findings do reinforce the conclusion that disseminating information and building knowledge is one small component of HIV prevention strategies. There are numerous contextual constraints to implementing any and all of the ABC behaviors, especially for women and girls, and these contextual issues need to be addressed simultaneously, and some have argued, before, to enable both women and men to enact these behaviors. These findings provide a strong rationale for choosing approaches that extend beyond the simple provision of prescriptive ABC messages, to more broadly influence the social norms and policies that serve as barriers to the adoption of safer behaviors, such as addressing perceptions of masculinity and norms of male behavior, targeting the social and structural causes of transactional and cross-generational sex, and curtailing gender-based violence.

There are certain limitations to the study that are important to highlight. It is unclear how generalizable the findings are beyond the sample population in Kenya, or how much the findings can be applied to other contexts. For example, the negative views toward condoms among this sample in Kenya may not be seen in other countries. There were various attempts, such as via random selection of sites and systematic sampling, to obtain representative samples of both male and female in-school youth and a general working adult population, yet these samples are still not representative of the whole community. While this as a case study of potential challenges in promoting the ABCs, one might expect (and should be 


\section{Hgrizons}

prepared to address) considerable variation in trying to promote the ABCs in different settings and among different audiences. Secondly, there may have been some confusion in the translations of the ABC behaviors. These terms were translated directly, so some of the meaning in English may not have been conveyed. However, to minimize confusion as much as possible, the surveys were translated from English into Kiswahili and back-translated into English by local researchers with relevant experience. Finally, the survey methodology used has some inherent drawbacks. An "assisted" self-administered survey was applied to the groups, to permit enhanced privacy and minimize concerns about confidentiality, yet this also resulted in the some of the questions not being answered by some participants.

An ongoing HIV prevention intervention in Naivasha, being implemented by FHI, builds on the study findings by bringing together various NGO, civil, and faith-based organizations to coordinate a prevention strategy that is balanced and does not include messages that contradict one another. The ongoing intervention focuses on interactive and interpersonal activities, such as discussion groups and street theater. In-depth discussions about sensitive social norms, relationship scenarios, and topics about sexuality take place during these activities. The intervention also combines both materials and messages on a more massive scale, such as billboards, to reinforce these messages. And finally, there are ongoing attempts to integrate complementary activities, such as gender-based violence reduction programs. 


\section{References}

Altman, L.K. 2005. “U.S. blamed for condom shortage in fighting AIDS in Uganda,” The New York Times, August 30.

Barnett, T., and J. Parkhurst. 2005. "HIV/AIDS: Sex, abstinence, and behavior change,” Lancet 5: 25.

Central Bureau of Statistics (CBS) [Kenya], Ministry of Health (MOH) [Kenya], and ORC Macro. 2004. Kenya Demographic and Health Survey 2003. Calverton, Maryland: CBS, MOH, and ORC Macro.

Green, E. 2003. “The new AIDS fight: A plan as simple as ABC,” The New York Times, March 1. http://physconsortium.com/pdfs/uganda_new_aids_fight.pdf

Halperin, D.T. 2004. "The time has come for common ground on preventing sexual transmission on HIV,” Lancet 364: 1913-14.

Osborne, K. 2005. “The ABC of HIV: It’s not that simple,” AIDS Summary 10: 2.

http://www.ippfwhr.org/publications/serial_article_e.asp?PubID=20\&SerialIssuesID=144\&ArticleID $=308$

Parker, R., D. Easton, and C.H. Klein. 2000. "Structural barriers and facilitators in HIV prevention: A review of international research,” AIDS 14(Supp 1): S22-S32.

PR Newswire. 2003. "Johns Hopkins: Namibia research shows most youth don't understand the terms 'abstinence' or 'faithfulness' for HIV prevention,” May 23. http://www.aegis.com. Accessed September 9, 2005.

Pulerwitz, Julie, Johannes van Dam, and Natalie Phillips-Hamblett. 2003. "The ABCs and beyond: Developing an operations research agenda on comprehensive behavior change approaches for HIV prevention," Horizons Final Report. Washington, DC: Population Council.

Rothenberg, R., J.J. Potterat, and J.P. Koplan. 2005. "The algebra of condoms and abstinence,” Sexually Transmitted Diseases 32(4): 252-254.

Shelton, J.D., et al. 2004. "Partner reduction is crucial for balanced 'ABC' approach to HIV prevention,” BMJ 328: 891-3.

Stoneburner, R.L. and D. Low-Beer. 2004. "Population-level HIV declines and behavioral risk avoidance in Uganda,” Science 304: 714-8.

The Economist. 2005. “Too much morality, too little sense.” July 28. http://www.economist.com/opinion/displayStory.cfm?story_id=4223619 


\section{Hgrizons}

UNAIDS, UNICEF, and WHO. 2004. "Kenya 2004 update: Treat 3 million by 2005. Epidemiological Fact Sheets on HIV/AIDS and Sexually Transmitted Infections.”

Wambugu, S. 2005. FHI, personal communication on November 10.

Wawer, M.J., et al. 2005. "Declines in HIV prevalence in Uganda: Not as simple as ABC," $12^{\text {th }}$ Conference on Retroviruses and Opportunistic Infections. Abstract available at: http://www.retroconference.org/2005/Home.htm.

Wilson D. 2004. "Partner reduction and the prevention of HIV/AIDS,” BMJ 328(7444): 848-9. 


\section{Hgrizons}

Horizons is a global operations research program designed to:

- Identify and test potential strategies to improve HIV/AIDS prevention, care, and support programs and service delivery.

- Disseminate best practices and utilize findings with a view toward scaling up successful interventions.

\section{(P) Population Council}

Horizons is implemented by the Population Council in collaboration with

- International Center for Research on Women (ICRW)

- International HIV/AIDS Alliance

- PATH

- Tulane University

- Family Health International (FHI)

- Johns Hopkins University

For more information, please contact:

Horizons Program, Communications Unit 4301 Connecticut Avenue, NW Suite 280 Washington, DC 20008 USA

Tel: 202-237-9400

Fax: 202-237-8410

Email: horizons@pcdc.org www.popcouncil.org/horizons 